he red globules, a homogeneous clot is formed. If only a portion coagulates, the romainder will be deposited upon the clot first formed, after it shall have contracted in 1 fi perpendicular direction sufficiently to Gqueeze out a serous fluid, still retaining the additional fibrin in solution. When all the ofbrin has coagulated, true serum remains, and the buffy-coated coagulum is evident. It will thus appear to be a part and parcel of the same phenomenon, namely, the coagulation of the fibrin, some delay occurring from a cause not understood, but which will be made evident when we know by what means the fibrin is held in solution by the serum.

I believe this explanation to be free from the many objections to which the other hypotheses are open, and if you, Sir, consider it worthy a place in your valuable Periodical, by inserting it you will greatly oblige, yours truly,

William Bird Herapath, Old Park, Bristol, Dec. 11, 1841.

\section{MR. MULHOLLAND'S FRACTURE APPARATUS.}

To the Editor of THE Lancet.

SiR,-During a practice of many years, I have often thought that there was required an instrument, on an improved plan, chiefly for compound and comminuted fractures of the leg and ankle-joint, which would save the patient much suffering, and be of great convenience to the surgeon. Such an instrument I have invented, and it embraces the following advantages, now submitted to your consideration, and that of the profession in general. I have the honour to be, Sir, your very obedient servant,

Joseph S. Mulholland, Surgeon.

Belfast, Dec. 10, 1841.

1. The frame of the instrument, which is very simple, forms a firm and steady foundatiou, when placed on a bed, whether hard or soft.

2. Upon the framework is erected a double inclined plane, with two pillars or supporters on either side, each a foot high. These pillars, attached to the frame by hinges, admit of being turned down, to allow the limb to be more conveniently laid on the plane, which also may be laid flat for that purpose.

3 . The plane may now be elevated at pleasure, and supported by two pins passed under it, through the pillars, and keyed, rendering the instrument exceedingly firm and secure against being overturned, by the involuntary starting of the patient during sleep, \&ic.

4. The pillars also support the weight of the bed-clothes, and prevent the limb from accidentally slipping off the plane, whether elevated or lying flat.

5. When necessary to alter bandages, dress sores, or otherwise attend to the soft parts, the pins being withdrawn and the pillars turned down, the plane now rests steadily and securely on a rack graduated by the scale of the pin-holes. The patient is thus saved the pain attendant on change of position, the dressings are more easily effected, the limb is kept cooler in the elevated position (which favours the return of the blood), than when lying flat on a bed in fracture-box, junks or cradle. Besides, a stiff knee-joint may be, in a great measure, prevented by this instrument, by moving the leg-plane on its hinge as soon as the limb can conveniently bear the motion.

6. There is a movable foot-board with side-pieces which receive the foot and prevent lateral motion, and which, by means of a simple screw, adapts itself to the length of the patient's limb, which may be ascertained at any time by measuring the sound one from the bend of the knee to the heel. In case of a very oblique fracture, the foot may be secured to the foot-board so as to effect extension; or, if necessary, counter-extension can be made by means of the pillars, or by the necessary splints, which can be arranged to great advantage on the instrument.

7. The lower end of the apparatus is a plane for younger persons, regulated as above described.

The instrument consists of twelve pieces so arranged by hinges, as to be quite easy of application, and convenient for packing, and, though last not least, not expensive.

\section{QUESTIONS}

RELATIYG TO TIE EVIDENCE OF

\section{MEDICAL WITNESSES AT CORO.} NERS' INQUESTS.

Wust the coroner procure the evidence of a particular medical man, and then order post-mortem examination.-Persons taken deud out of the water.-Question of medical evidence at every inquest.

\section{To the Editor of THE LANCET.}

Sir,-. To you, as coroner for the great metropolitan county of Middlesex, I beg to submit the following queries:-

First. In sudden deaths, whether by violence or otherwise, on which inquests are held, is the coroner compelled by law to obtain the evidence of the medical man who may have seen the case immediately before death, or been present just at the death, or immediately after death ? And then, if asked to state his opinion of the cause of death, is it compulsory on the coroner to order a post- 
mortem examination to be made, to enable that opinion to be given? I fear, from personal experience, that very many of our country coroners are most willing at all times to dispense with medical evidence, even if the case be shrouded in doubt, either from want of judgment (not being medical men) to discriminate what cases require such evidence, or to serve their personal convenience in some way.

I was lately called to a man who had been under water (as I was informed) for twenty minutes. Resuscitation was attempted in vain by myself and another medical gentleman. I was solicited, on departing, by the policeman in attendance, to give my name, to be submitted to the coroner in the list of witnesses at the inquest, to which, however, I was never summoned. Now, there might have been marks of violence on the body, which would require medical evidence to explain to the jury; or he might have laboured under the effects of poison at his death; or, although taken lifeless from the river, other causes may have operated in causing his death, besides drowning. Surely, for the trifling expense to the county, it would be most advisable to have invariably a medical man's evidence, if present at the death, or, even without that qualification. Even if his evidence was not required to clear up the facts, in ninety-nine cases out of a hundred, yet were it better far that such should be the consequence than that the hundredth death should be left in mystery, and perhaps a shield thrown over a murderer. I am, Sir, your very obedient servant,

$$
\text { W. B. M'EgAN, M.R.C.S.R. }
$$

\section{Chelmsford.}

1. In reply to the first question we have to observe that the Coroner was not compelled by law to summon the medical practitioner. Nor is he required to order a post-mortem examination, to enable the medical witness, when summoned, to state his opinion of the cause of death. The particular circumstances in each case must guide the Coroner in the exercise of his discretion. Then a majority of the jurymen sitting at any inquest require the Coroner, in writing, to summon a medical practitioner whom they have named, and direct him to make a post-mortem examination of the body, the Coroner is obliged by law to comply with that requisition. This useful power is given to the majority of the jurymen by the Medical-Witnesses' Act.

2 . It would be useless and probably mischievous to require post-mortem examinations in all cases of death by drowning. For example. When a boat is upset, and the crew or passengers in it are seen by several persons to sink into the water, and are drowned, of what use, so far as a judiont inquiry is concerned, would be a medical examinotion of the bodies? Again. When persons are seen skating, or sliding on ice; and are observed by numbers of individuals to fall in and drown, why should there be dissections of the bodies? The public would not, in such cases, tolerate either the operations, or the expenses; and if the inspections were enforced, the practice would soon have the effect of raising so strong a prejudice against medical practitioners, that medical testimony would be either altogether re jected, or entirely undervalued in cases where it was absolutely necessary to fulfil the ends of justice.

3. Mr. M'EGAN has not stated in what manner it was either known or supposed that the body of the man mentioned by him had got into the water. Consequently, we are incapable of determining what was the precise duty of the Coroner on that occasion. If the evidence of a suicide, or of an accidental death, proved to be perfectly conclusive to the minds of the Coroner and Jury, that was sufficient. But if the man was simply found dead in the water, and the cause of his death was involved in mystery, then, undoubtedly, the more prudent course for the Coroner to adopt would be to issue an order to the medical practitioner who was first called in to see the body, to make a post-mortem examination, and thus obtain the most satisfactory information to be presented at the inquest on the first assembling of the jury. This is a rule of practice which we have observed with excellent eflect for some time past, and it is one that we intend steadily to pursue.

Surgeons in attendance before death.-When is medical testimony necessary.-At uhose discretion, or by what law is it to be cited. -Is every inquest a medico-legal inquiry.Registrars of deaths.

\section{To the Editor of THE Lancet.}

Sir,-Permit me through Tue IanceT to ask information upon the following point :-

A poor woman in my neighbourhood, after her usual employment in the culture of a piece of ground, was suddenly seized with illness in the forenoon of Saturday. Although medical aid was sent for immediately, nothing material was done for her until three o'clock, when I saw her, at the earnest request of her husband, and found her suffering from effusion on the brain ; the usual symptoms, insensibility, stertorous breathing, \&c., 
Delmg present. : With difficulty I bled her to hbout gix ounces, and then suggested that Ge should be conveyed to the union workHouse; away from the extreme poverty and uncomfortable state of her own dwelling; but before the litter could arrive the poor woman died. Presently the registrar called upon me to ask the cause of death; I replied by desiring him to state the facts to the coroner, saying that I should be ready to give evidence if required. Next day the parishbeadle informed me that an inquest would take place on Monday, which it did, but certainly without medical testimony having been asked or required. Now, it appears to me that if it were necessary in this case to inquire into the cause of death, it was necessary to have the only material evidence obtainable upon the occasion, namely, that of the medical attendant. Some time ago a jury was called together to inquire into the cause of death in a patient of mine, in very redueed circumstances, who had been safely delivered about ten days before. She was so far recovered after her confinement as to be able to receive visits, and was actually sitting at tea with her mother and a friend, when her husband, an idle and misbehaving man, suddenly appearing, some high words passed between them, and she was seized with giddiness, and fell back in her chair and expired. In this instance I received a sum. mons to attend an inquest on the body. I shall thank any gentleman, and more especially Mr. Wakley, who can speak $e x$ cathedr $\hat{a}$ upon the question, to point out the cases in which medical testimony is required, and when not, for I am quite at a loss to determine. Is it in the breast of the coroner, or is the law declaratory on the point? The small fee paid to the medical witness is, of course, not an object in summoning or declining medical evidence. Beck, in his "Mertical J urisprudence," at page 483 , when remarking apon the duties of the coroner, thus expresses himself:-" Death, even when the consequence of disease, is often an unexpected event. But if an individual expire under his own roof surrounded by friends and relatives, we are disposed to consider it as an ordinary dispensation of Providence, and one to which all of us are, sooner or later, doomed. The features of the case differ materially when a person is found dead on the highway, or the banks of a river, or in a lonely place. Indeed, if he be discovered to have paid the last debt of mortality either in a sudden manner or at a distance from his house, the laws of civilised society demand an investigation of the cause, and over this investigation the officer called a coroner is appointed to preside. It will readily be observed from the above remarks that the office in question is an important one; the duty of the coroner extends to an examination of the circumstances connected with every case of sudden or suspicious death; and he is to make this with the aid of a jury, summoned by him for the purpose. Future proceedings are regulated by the verdict they may pronounce."

Then follow some observations bearing upon the question of appointing medical men to the office of coroner (which I forbear to quote, though decidedly in favour of the measure, because coram non judice), and finishing with these words :- "Every inquest involves a medical question; and even though the case may at first sight appear so clear, and the facts so certain, as hardly to need a professional examination, yet there will be often occasion to regret, afterwards, that a medico-legal dissection had not been pursued." I deem it needless to observe upon this judicious remark, and shall be glad to be favoured with any opinions tending to elucidate the law, which equally interests the profession and the public. I am, Sir, your obedient servant,

Wandsworth.

Thomas Chapman.

1. We have already in the two last Numbers of THE LANCET adverted, at very considerable length, to the classes in which the two cases cited by our correspondent are obviously included. When deaths occur suddenly, -in the absence of the remotest suspicion that they have been produced otherwise than from natural causes, - when not the shadow of a doubt exists as to the lawful nature of the fatal result,-then it is not our practice to summon medical witnesses, and direct post-mortem examinations of the bodies.

2. In the second case described by $\mathrm{Mr}$. CHAPMdN, we think it was right that he was summoned to the inquest; and we are of opinion also that he should have been directed to make a post-mortem examination of the body ; because it was inferred that the death had been caused by the violent lan. guage and gestures of the woman's husband; and threats, in some cases, are not less effectual in killing than are blows in others. The misconduct of the man required, by way of example, a searching investigation into the facts of the transaction. It might have been discovered that there were blows as well as threats.

3. The rules that we have already ex. plained, in the two last Numbers of our Journal, are perfectly simple and easy of observance, viz., first, not to call in medical evidence in cases of sudden death where the facts are clearly, distinctly, and incontestably proved by the spectators of the event; and, secondiy, never to orit requiring medical 
testimony when the circumstances of the death are involved in mystery or suspicion.

4. In certifying for the Registrar of Deaths, medical practitioners do not hesitate, in the generality of instances, to describe the SPECIFIC cause of the dissolution uithout having made an "examination of the body. From this it is understood that they testify to the best of their judgment, believing the death to have been a natural one. What would be said if they, in all cases, refused to certify without first making dissections of the dead? Precisely the same question applies to inquests. If either the Coroner, or the medical practitioner, or even the constable, or a neighbour, can discover a single fact on which might rationally be founded a suspicion that in a case of sudden death the event had not occurred in the course of nature, nothing ought to satisfy either the Coroner in holding the inquest, or the medical practitioner in certifying to the registrar as to the nature of the death, without ascertaining, by a medical inspection of the internal organs of the body, what had been the precise cause of the fatal result.

\section{Medical evidence in a case of death from an operation on the ear.-Want of medical coroners to conduct medical inquiries.}

\section{To the Editor of THE LANCET.}

Sir,-During a temporary residence in the country to recruit my health, I have remarked the frequency with which the minor operations of surgery are performed, and as many of your readers may not be aware of their attendant results, I will briefly relate the principal features of an interesting case which recently came under my own observation at Barnstaple, in North Wevon.

An advertisement appeared in the weekly papers of the town anmouncing the intended visit of a Dr. Cronin, to perform an operation for the cure of deafness, which, I may inform you, consisted in injecting heated moist air into the Eustachian tube, through the lower meatus of the nose. Accordingly, the doctor came, and a school-master, Mr. R. Page, had the operation performed, on 'Thursday, the 12th of August. It was followed up on the Friday and Saturday, but with little benefit, and considerable excitement to the patient. In the evening of the last day profuse hæmorrhage from the nose, and diarrhoea, supervened, and he continued with slight alternations of better and worse until the following Wednesday, when symptoms more alarming commenced; he complained of a strange heaviness in the head, and at length delirium ensued. It was now judged proper to obtain other than Dr. Cronin's assistance, and a Dr. Budd was called in, who administered anodynes, and gave no hopes of his patient's recovery. On Saturday afternoon the delirium increased, and he constantly exclaimed, "Pump the gas out of my head which you have pumped into it. It is the gas that has done it. I wish I had not gone to the doctor at all." The pain now became excessive in the forehead, temples, and ears, until five o'clock on Sunday morning, when he died.

It was reported in the town that his death was the result of the operation, and an inquest was loudly demanded. The coroner, a legal gentleman, was non est inrentus, but by five o'clock on Monday evening a deputycoroner was found, who summoned a jury. It may be remarked that the absent coroner had but recently been elected, by a majority of one in the town council, and upon that occasion the necessity of the coronership being placed in the hands of a medical man was inculcated, the unsuccessful candidate being of that profession.

The jury required the evidence of only one medical man (Dr. Budd), who gave his evi. dence as follows :- "The patient, Mr. Page, undoubtedly died of inflammation of the membranes of the brain, but how it was pro. duced I do not know. It might arise in a hundred ways."-" The operation shocked the nervous system, but decomposition is too far advanced to enable the existence of recent inflammation to be detected, and the examination now of the body could not prove whether death was caused by the operation or not!!"-" The operation is dangerous; it has caused rleath in the hands of an eminent educated physician, Dr. Turnbull!! It is like firing an air-gun into the ear; but if an examination of the body had been made immediately after death, we should have discovered whether the drum of the ear showed inflammation; but decomposition now forbids it !!"

Here the examination terminated, when it was proposed to send for Dr. Cronin, the operator. This resolution, strange to say, was negatived by a majority of one; and the jury, having retired, soon returned the following verdict :- " That the deceased died from inflammation of the brain; but whether produced by recent operation, or by natural causes, the impossibility of a satisfactory examination of the body of the deceased, in consequence of its decomposed state, precludes the jury from judging."

Was this a proper inquest, evidence, and rerdict? A medical-man coroner could have informed the jury that within forty-eight hours decomposition does not take place; and whilst we deplore the investigation which was lost to science, and the possible gratification which might have been given to private feelings, let us hope that the record 
of many similar cases will convince the public that medical men are peculiarly adapted for the office of coroner, and it equally for them. I am, Sir, \&c.*

H. M. W.

1. The inquest in this instance certainly does not appear to have been very wisely conducted. At the same time we do not feel called upon to condemn the evidence of Dr. Bupd, Our correspondent is quite mistaken in supposing that decomposition of the body does not occur so soon as forty-eight hours, as we have seen it happen in a case of sudden death, not attended by any peculiar circumstances, to such an extent, in nineteen hours, as to render an examination of the body not only utterly useless, but one of the most repugnant and dangerous nature. The subject of that case was a law-student, who had died, instantaneously, from disease of the heart. He was a young man of prudent and temperate habits, twenty-one years of age, and of moderate height and size. The decomposition had been so rapid that in less than twelve hours after his death, not a feature of his face was recognisable by the nearest relative.

2. The operation described by our correspondent certainly killed one person in London; but if there be an interval of ease and heaith, of only a few hours' duration, between such dangerous experiments and fatal catastrophes, non-profrisional juries appear to be anwilling to trace causes and effects in such calamities; and, unfortunately, although they be conducted by first-rate anatomists and pathologists, the examinations prove but of little value even to the mind of the medical practititioner. How can it be otherwise in cases in which the nervous system is so completely involved? If opinion weigh not, in evidence, as fact,-and such a ponderous force cannot be safely yielded, in a judicial inquiry, to what may prove to be only a loose conjecture,-the guilty experimentalists must generally escape without suffering any other punishment than the detection of their dangerous impostures.

Evidence of medical men, with or without the fee.-Death from violence; the surgeon not summoned at the inquest.

To the Editor of THE LANCET.

Sir,-Your opinion on the following cases will greatly oblige me :-

* This letter was authenticated.-ED. L. No. 956.
I was yesterday called to a boy who had been run over. He was dying. He bled profusely from the right ear, mouth, and nose ; there was an extensive fracture of the skull, with depression of bone, and he lived only about three minutes after I saw him. An inquest was held to-day over the body by Mr. Iveson, of Hedon, near Hull, the coroner for this district. I was not summoned to attend, although the only medical man who saw the case. Not being satisfied with the coroner's neglect (he having behaved in a similar manner in a former case, which $\mathbf{I}$ will presently relate), I determined to see what was going on in the jury-room, as a spectator, not a witness.

I entered about an hour after they had assembled, and the foreman acquainted the coroner that $I$ was the medical man who had seen the case. The coroner presently said, "Will you give your evidence in this case?" I replied, "No, Sir, I have not been summoned, and will give no evidence unless I have the usual fee."

Coroner: "I should not have asked for your evidence if I had not intended giving the fee."

My evidence was then taken. The coroner handed me the fee, with the following observations:- "Sir, if I like I could have you sent to York Castle for refusing evidence in this case. I had the power to compel your evidence without a fee, although not summoned. You were in the jury-room; that was sufficient. I can call upon any one in the room, whom I think proper, for evidence, and can have them punished for a refusal."

I told the coroner I differed from him in opinion, and would again refuse evidence, under similar circumstances, unless $I$ was to have the fee.

The other case to which I allude was as follows :-

About four months ago $I$ was sent for to a man who had been severely hurt by a horse; I found his skull dreadfully fractured, with the brain protruding. He was still living. $I$ did all I could for him in the shape of removing the loose bone and elevating what was depressed, \&c., and attended him up to his death, which took place about twenty-four hours after the accident.

An inquest was held on the body, also by MIr. Iveson. I was not sent for to give evidence, although witnesses were very scarce, there being only one man present when the accident occurred. I was on the spot within a very few minutes after the accident, therefore I think the coroner scarcely did his duty in not sending for me.

$W$ ith reference to the above cases, $I$ wish to know if I had the law on my side in refusing evidence in the above case, unless $I$ had the usual fee: also, whether the coroner was justified in not taking my evidence in $2 \mathrm{Gr}$ 
the case of the man killed by the horse. Your most obedient servant,

Thomas Wilson.

Hornsea, Nov. 27, 1841.

1. The causes of death in these two cases could probably be better described, or more satisfactorily proved, by witnesses of the accidents, than by any medical practitioner who was called in after their occurrence. A man, in perfect health, is cleaning a horse. His head is presently hit to pieces by a kick from the animal. The circumstance is witnessed. Not a shadow of doubt exists in the case. The Coroner and Jury might fairly conclude that medical testimony in such an inquiry was not necessary.

2. The same thing may be said with respect to the inquest on the boy who had been run over by some rehicle,-that is, supposing there were any observers of the infliction of the injuries. If the boy had been found in the road, insensible, and dying, and it was not known in what manner he was wounded, then, unquestionably, medical testimony was imperatively demanded. Nearly everything depends, in such cases, on the fact whether there be criminality, or culpability, attached to any persons, - whether there were any witness of the transaction,-and whether the credibility of the casual witness or witnesses who are produced is undoubted. Nothing, as we have already repeatedly stated, can be more injurious to the value or weight of medical evidence, in important inrestigations, when circumstances of a criminatory nature exist, than to demand it on all occasions and constantly, when the facts can be as well, or more effectually, proved by Join Noakes or Tom Stiles.

3. With respect to the power of the Coroner in demanding the evidence of the medical gentleman, because the latter happens to be in the court, Mr. WrLsos was distinctly right in his law. of the case, and the Coroner as distinctly wrong. Before the Coroner had power to commit the medical gentleman for contempt, it was necessary that he should have caused a summons to be served upon him according to the form laid down in the Medical-Witnesses' Act. In the absence of compliance with the provision in that statute, had the Coroner committed Mr. Wilson, he would, at the same time, have committed himself into a far worse predicament than a gaol. A judge is but a very weak instrument of authority when he himself is a vio- lator of the law. In such instances he only becomes dangerous to himself. If a medical practitioner, without the authority of the Coroner, makes a post-mortem examination of a body, and thus puts himself, nolens volens, in possession of the cause of the death, he can be compelled to attend the court by a common summons, and required to state the facts which he discovered in making such examination, and, in the event of his refusing to give evidence, he might be committed for a contempt of the Court.

Suspicious symptoms. - The inquest demanded; objected to; held; no post-mortem alloued.

\section{To the Ealiter of THE LAxceT.}

Sir,-An inquest was held on the body of a poor woman in this neighbourhood, wherein I beg your impartial opinion with respect to my professional conduct on the occasion, which has been bitterly assailed.

Elizabeth Edwards, previously engaged at her usual laborious domestic avocations, on the morning of the 15 th instant was suddenly attacked with what the attendants called a kind of fit. Called in at four, p.m., I found her greatly depressed, attempting to vomit, with serere convulsive action about the larynx and trachea. I considered it to be an attack of hysteria, and prescribed accordingly. In four hours I found the symptoms increased, the attempts to romit almost incessant, a burning pain at the pit of the stomach, the extremities livid, and covered with profuse cold sweats, countenance anxious, tongue dark-coloured and swollen, with considerable frothing at the mouth and nostrils. She died at two, a.m., next day, without exhibiting any further indication that the brain was affected. Knowing her passions to be riolent, and that she was greatly excited from a drunken husband having wantonly left his home, I concluded that she had either taken or been affected by corrosive poison, especially when reflecting on the extraordinary circumstances attending the inquest, which, as a duty to society, I demanded should be held.

The only "witnesses examined, excepting myself, were two persons who had only seen her after the attack, and a young girl who deposed that she had complained the day before of a pain in the back of her neck, which had not prevented her from following her usual employment. No witness was called to prove how the attack commenced, nor the charwoman who was with her from first to last, and during the preceding day or two, notwithstanding my urgent entreaty.

The coroner offered four reasons for supposing that she died a natural death, which appeared to satisfy the jury :- 
First. That she died from hysteria. This opinion I refuted by stating that she had no symptoms of fit of any kind, or congestion of the brain, after I saw her.

Second. That she died from internal hæmorrhage. This was so contradictory to the first supposition, and to the symptoms, that $I$ at once declared it to be impossible.

Third. That the body would have been more decomposed. But I stated that arsenic and some poisons would actually preserve the body, indefinitely, as the recent French discoveries proved.

Fourth. That if I had suspected poison, I would have administered an antidote. To this I replied, that had I known what poison was taken, I could easily have supplied one; under the circumstances $I$ ordered copious draughts of gruel, and administered enemata. The verdict returned was, "Died by the visitation of God." No post-mortem was allowed.

The inquest was at first resisted by the local authorities; and $\mathbf{I}$ now ask you, $\mathrm{Sir}$, Was I justified in demanding it, and whether the symptoms abore described, and detailed to the jury, rendered it probable that poison had been introduced into the tissues of the body? I am, Sir, yours very truly,

Thomas Enwards.

Llansffroid, near Oswestry, Nov. 25, 1841.

A judgment of the conduct of the Coroner in this case must, we suspect, be determined by circumstances, which had come to his knowledge before the inquest was held, and the nature of the non-professional testimony of the witnesses during the inquiry. If the woman was attacked suddenly, when individuals were present whose testimony was without taint or suspicion, the Coroner and Jury might reasonably conclude that medical evidence was not requisite. On the other hand, if the patient was found in a state of insensibility, and continued to the time of her death in that condition, and her previous distress of mind, together with the symptoms of the disorder, furnished ground for believing that she might have taken poison, then a medical examination of the body ought to have been instituted, in order to complete the investigation. In the performance of their public duties, it should be recollected that Coroners and medical practitioners are entilled, respectively, to entertain independent opinions in all cases of death which are submitted to their notice. It is, we fear, too much the practice to visit mere differences of decision with attacks upon the integrity of motives.

\section{Under what summons medical men should attend.}

To the Editor.-Sir, Am I compelled to attend a coroner's inquest from receiving the sumnons of the beadle only? Last week one of these warrants was brought to my house to attend an inquest at St. Bartholomew's Irospital. I intimated to the beadle that $I$ could give no evidence, and that consequently there would not be the least use in my attendance; but he replied that he had been ordered to summon all who knew anything of the case. I have often received these warrants, and beg to know the law respecting them. I remain, Sir, your obedieut servant,

\section{December 13, 1841.}

\section{INVESTIGator}

The ordinary summons which a constable serves upon a witness is issued by that offcer under a warrant which he has received from the Coroner. All witnesses, medical as well as others, are bound to obey a summons so served; but when gentlemen of the medical profession attend at inquests in consequence of having been supplied with this legal process, they are not bound by law to furnish the Court with medical evidence. They may refuse to be examined profes sionally, unless they first receive a summons for their attendance and evidence, according to the form prescribed in the Medical-Witnesses' Act, which summons, to be valid, must be signed by the Coroner himself. After submitting to an examination under the authority of a summons so signed, the medical witness can enforce the payment of his fee, or fees, at law. If his testimony be given when he does not possess such a summons, payment of the fce may be legally refused by the Court. The common summons, therefore, must be obeyed, so far as attending at the inquest, and giving evidence as an ordinary witness. But professional evidence cannot be enforced under such a summons, unless the medical practitioner has opened the body without the sanction of the Court, and thus improperly placed himself in the possession of facts, which facts he is in that case bound to disclose without a fee. From what we have just stated, we hope it will be clearly understood that the provisions of the Medical-Witnesses' Act have not, in any respect, weakened the force or the authority of the ordinary summons which is served by the constable under the authority of the Coroner's warrant. 